\title{
Drive times habit in human eyelid conditioning'
}

\author{
WILLIAM F, PROKASY, PENNSYLVANIA STATE UNIVERSITY \\ CHARLES K. ALLEN, UNIVERSITY OF MONTANA
}

The theory that drive multiplies with habit implies that performance differences between two groups with different drive should increase across trials, and that variances should be greater with increased drive. Data from human eyelid conditioning analyzed in the units of the theory did not support either prediction.

When UCS intensity is increased, both drive (D) and habit $(\mathrm{H})$ are increased (Spence, Haggard, \& Ross, 1958)。 Therefore, an increase in UCS intensity should produce effects similar to, but greater than, those accompanying an increase in $\mathrm{D}$, since $\mathrm{H}$ is also increased. It would be predicted, therefore, that performance differences between high and low UCS-intensity groups should increase across trials and that between-S variance should be greater during the last half of training. Since individual difierences in $\mathrm{H}$ are also multiplied by $D$, between-S variance should be greater with an increased UCS intensity.

\section{Method}

Apparatus. The CS was a 500-msec. 1000-cps tone of $82 \mathrm{~dB}$ superimposed on a $77 \mathrm{~dB}$ white noise background. The UCS was a corneal air-puff of 50-msec. duration and sufficient pressure to support either a 200 -(high) or 100-(low) mm column of mercury, and was delivered at CS offset. Response pickup has been described elsewhere (Prokasy \& Whaley, 1962) and recording was done via an Offner Type RC Dynagraph. A CR was defined as a deflection of at least $1 \mathrm{~mm}$ of the ink-recording pen occurring between 148 and $524 \mathrm{msec}$. after CS onset. A Western Union transmitter programmed the trials with a 12-sec. average intertrial interval.

Procedure. The two orthogonal independent variables were UCS intensity and a standard conditioning procedure (e.g., Prokasy \& Whaley, 1962) versus a guessinggame masking procedure (e.g., Spence, Homzie, \& Rutledge, 1964). The group labels will be: $H N$ for high intensity and normal procedure; LN for low in- tensity and normal procedure; HM for high intensity and masking procedure; and LM for low intensity and masking procedure. All Ss were given $10 \mathrm{CS}-a l o n e$ and $10 \mathrm{UCS}-a$ lone adaptation trials in a random order followed by 300 paired trials and 50 extinction trials. Extinction data will not be reported.

\section{Results}

Individual response probabilities were converted to excitatory potential (E), as described by Spence (1956). Table 1 provides median $\mathrm{E}$ in blocks of 20 trials in two ways: for all Ss, and then for those Ss not meeting the criterion of being a voluntary-form-responder. ${ }^{2}$ Two expected effects were obtained: higher response levels with the higher intensity $(\mathrm{F}=11.99, \mathrm{df}=1 / 236)$ and higher response levels with the typical conditioning procedure $(\mathrm{F}=34.42, \mathrm{df}=1 / 236)$. The small negative values of Rho show that the differences between Groups HN and LN and between Groups HM and LM did not increase across trial blocks.

Table 2 provides between-S variances for trials 1-150 and 151-300. All variances increase from the first to the second block, though no increase is significant ${ }^{3}$ Contrary to prediction, the larger variances were obtained in Groups LN and LM, though the effects were significant only in the former case.

\section{Discussion}

According to the theory that $\mathrm{E}=\mathrm{D} \times \mathrm{H}$, the increase in mean performance which accompanies an increase in $D$ results from divergence across trial blocks in the performance differences of high and low D groups. Although there exist some data which show trends to divergence (e.g., Spence, 1958, Fig. 2), there are also data which show, if anything, convergence (e.g., Spence, 1958, Fig. 5). In no prior instance has an appropriate statistical test been made. The tests made in this study fail to support the hypothesis of divergence between groups, although it is possible that some unusual interacting between the $\mathrm{H}$ and $\mathrm{D}$ components of UCS

Table 1. Median E Values (times 1000) in Blocks of 20 Trials

\begin{tabular}{lccccccccccccccccc} 
Group & $\mathrm{N}$ & 1 & 2 & 3 & 4 & 5 & 6 & 7 & 8 & 9 & 10 & 11 & 12 & 13 & 14 & 15 & Rhoa \\
\hline $\mathrm{HN}$ & 60 & 2325 & 2900 & 3253 & 3842 & 3842 & 3919 & 4036 & 4016 & 4201 & 4106 & 4282 & 4106 & 4282 & 4282 & 4201 & \\
$\mathrm{LN}$ & 60 & 1964 & 2615 & 3000 & 3524 & 3691 & 3724 & 3675 & 3842 & 3842 & 3842 & 3759 & 3954 & 4036 & 4016 & 4132 & -.31 \\
$\mathrm{HM}$ & 60 & 2325 & 2615 & 2963 & 3025 & 3319 & 3399 & 3441 & 3496 & 3569 & 3413 & 3441 & 3510 & 3691 & 3707 & 3598 & \\
$\mathrm{LM}$ & 60 & 1964 & 2168 & 2260 & 2476 & 2686 & 2615 & 2668 & 2757 & 2900 & 2937 & 3101 & 3126 & 3088 & 3126 & 3063 & -.10 \\
$\mathrm{HN}^{b}$ & 53 & 2168 & 2874 & 3176 & 3707 & 3842 & 3842 & 3842 & 3842 & 4036 & 4036 & 4036 & 4036 & 4282 & 4282 & 4036 & \\
$\mathrm{LN}^{b}$ & 47 & 1891 & 2476 & 2816 & 3190 & 3253 & 3293 & 3524 & 3774 & 3675 & 3842 & 3675 & 3842 & 3842 & 3842 & 4036 & -.30 \\
$\mathrm{HM}^{b}$ & 52 & 2325 & 2401 & 3000 & 3000 & 3253 & 3399 & 3427 & 3413 & 3569 & 3385 & 3385 & 3385 & 3644 & 3675 & 3568 & \\
$\mathrm{LM}^{b}$ & 54 & 1964 & 2215 & 2325 & 2476 & 2686 & 2615 & 2641 & 2757 & 2874 & 2874 & 3075 & 3126 & 3038 & 3126 & 3000 & .01 \\
\hline
\end{tabular}

$a=$ Rank-order correlation between ordinal trial block and size of difference between high and low intensity groups.

$b=$ With voluntary-form-responders removed. 
Table 2. Variances in $\mathbf{E}$ and $\mathbf{F}$-ratios Across Two Trial Blocks

\begin{tabular}{|c|c|c|c|c|}
\hline \multirow[b]{2}{*}{ Group } & \multicolumn{3}{|c|}{ Trials } & \multirow[b]{2}{*}{$\mathrm{F}$ (Blocks } \\
\hline & $N$ & $1-150$ & $151-300$ & \\
\hline $\mathrm{HN}$ & 60 & .468 & .613 & 1.31 \\
\hline $\mathrm{LN}$ & 60 & .898 & .933 & 1.04 \\
\hline$F(H N-L N)$ & & $1.92^{a}$ & 1.52 & \\
\hline $\mathrm{HM}$ & 60 & .579 & .706 & 1.22 \\
\hline$L M$ & 60 & .647 & .986 & 1.52 \\
\hline$F(H M-L M)$ & & 1.12 & 1.40 & \\
\hline $\mathrm{HN}^{b}$ & 53 & .311 & .498 & 1.62 \\
\hline$L^{b}$ & 47 & .869 & .933 & 1.08 \\
\hline$F(H N-L N)$ & & $2.79^{a}$ & $2.05^{a}$ & \\
\hline $\mathrm{HM}^{b}$ & 52 & .633 & .724 & 1.14 \\
\hline $\mathrm{LM}^{b}$ & 54 & .796 & 1.065 & 1.34 \\
\hline$F(H M-L M)$ & & 1.26 & 1.47 & \\
\hline
\end{tabular}

$a=p<.05, b=$ voluntary-form-responders deleted

intensity can account for this failure. The essential point is that the mean differences obtained cannot be construed as supportive of the theory in the absence of divergence between groups, as it is the latter which the theory predicts.

The outcome with variances, while not as predicted, need not be interpreted as a failure of the theory. Although not significant, the variances tended to increase from the first to the last trial block. The lower variance found with the higher UCS intensity can be interpreted, post hoc, with additional assumptions. If it is assumed that an increase in intensity serves notonly to increase $D$ and $H$, but also to reduce individual differ- ences in $\mathrm{H}$, i.e., enough to overcome and reverse the multiplicative effects of $D$, then smaller variances with higher intensities can be accounted for. However, the variance outcome together with the failure to obtain divergence, even though mean differences were obtained, points to a failure of predictive consistency for the $\mathrm{DxH}$ hypothesis within the same experimental setting.

\section{References}

Prokasy, W. F., \& Whaley, F. L. The intertrial interval in classical conditioning. J. exp. Psychol., 1965, 70, 464-472.

Spence, K. W. Behavior theory and conditioning. New Haven: Yale University Press, 1956.

Spence, K. W. A theory of emotionally based drive (D) and its relation to performance in simple learning situations. Amer. Psychologist, 1958, 13, 131-141.

Spence, K. W., Haggard, D. F., \& Ross, L. E. UCS intensity and the associative (habit) strength of the eyelid CR. J. exp. Psychol., 1958, 55, 404-411.

Spence, K. W., Homzie, M. J., \& Rutledge, E. F. Extinction of the human eyelid $\mathrm{CR}$ as a function of the discriminability of the change from acquisition to extinction. J. exp. Psychol., 1964, $67,545-552$.

\section{Notes}

1. This study was supported by NSF Grant G 18119 to William F. Prokasy. Charles K. Allen was a NIMH Postdoctoral Fellow at the Pennsylvania State University when this experiment was conducted. 2. A voluntary-form-responder was defined as a $S$ with a $C R$ slope of at least $60 \%$ of the slope of the UCR.

3. F ratios for variances were obtained by placing the larger variance over the smaller and adopting as the $5 \%$ level the tabled $F$ value for half of that, i.e., the $2.5 \%$ level. 